\title{
Raiva: uma doença antiga, mas ainda atual
}

\author{
Parte1
}

\section{Rabies: an antique disease, but still current}

\section{Resumo}

O objetivo principal deste manuscrito é fornecer informações técnicas e científicas sobre a raiva aos estudantes de medicina veterinária, veterinários e outros profissionais relacionados à saúde. Embora conhecida desde a antiguidade, atualmente ela é definida como uma zoonose negligenciada e permanece endêmica, especialmente em países em desenvolvimento, por causa de limitações financeiras e problemas de infraestrutura. Os morcegos hematófagos foram relatados como novos reservatórios da raiva na América Latina e no Caribe no início do século $\mathrm{XX}$, causando prejuízos econômicos na pecuária e mortes humanas, no entanto o mundo ainda está surpreso por causa dos lissavírus em morcegos não hematófagos na África, Oceania e Eurásia. Os vírus da raiva e os vírus relacionados à raiva, coletivamente denominados de lissavírus, podem ser distinguidos pela caracterização molecular em vários genótipos distintos, no entanto somente os vírus do genótipo 1 são costumeiramente referidos como vírus da raiva, enquanto todos os outros são chamados de lissavírus. Na taxonomia viral, o uso de técnicas moleculares disponíveis na atualidade possibilitou a inclusão de novas espéciesmembros no gênero Lyssavirus e revelou a existência de variantes distintas dos vírus da raiva distribuídas entre diferentes espécies animais em diferentes regiões do mundo. A colonização europeia da África, Ásia e do Novo Mundo teve papel importante na disseminação da "linhagem cosmopolita" do vírus da raiva através de cães que viajavam com os conquistadores e colonizadores. O vírus, uma vez estabelecido nas populações de cães, subsequentemente pode ter sido transmitido para novas espécies de reservatórios silvestres e evoluiu para distintas linhagens devido às mutações acumuladas ao longo dos séculos. Os hospedeiros reservatórios da raiva no mundo variam conforme as localizações geográficas.

\section{Summary}

The main objective of this manuscript is to provide students of veterinary medicine, veterinarians and other health-related professionals with scientific and technical information on rabies. Although the disease is known since antiquity, it is now defined as a neglected zoonosis and it remains endemic especially in developing countries, because of financial limitations and problems of infrastructure. The vampire bats were reported as new reservoirs of rabies in Latin America and Caribbean islands in the early 20th century provoking economic losses in livestock and human deaths, but still the world is astonished because of the lyssaviruses in non hematophagous bats in Africa, Oceania, and Eurasia. Rabies and the rabiesrelated viruses, collectively known as lyssaviruses, can be distinguished by molecular characterization into several distinct genotypes but only the genotype 1 viruses are customarily known as rabies viruses, whereas all others are referred to as lyssaviruses. In virus taxonomy, the use of the molecular techniques now available has augmented the species members of the genus Lyssavirus and revealed the existence of distinct variants of rabies viruses distributed among different animal species in different regions of the world. The European colonization of Africa, Asia and the New World played a significant role in the dispersion of the "cosmopolitan lineage" of the rabies virus through infected dogs traveling with the conquerors and colonizers. Rabies virus, once established in the dog populations, may then have been transmitted into new wildlife host reservoirs and evolved into distinct strains due to accumulated mutations through centuries. The reservoir hosts of rabies in the world differ according to the geographic locations. 


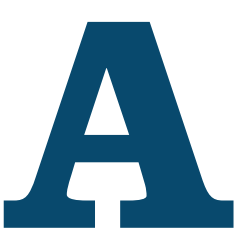

raiva é uma antropozoonose causada por um vírus do gênero Lyssavirus, caracterizada em animais e no ser humano por uma encefalite aguda fatal (ACHA; SZYFRES, 2003), ou "quase sempre fatal" (NILSSON, 1970; BELL et al., 1971) nos animais e "quase invariavelmente fatal" no ser humano (MACHADO, 1996).

O termo Hidrofobia é utilizado para designar a doença no ser humano (WILKINSON, 2002). No cão, popularmente é denominada de doença de "cachorro louco" e, em bovinos, como "raiva paralítica" ou "doença paresiante" ou ainda "mal das cadeiras", especialmente na América Latina (BAER, 1991).

A doença foi também denominada de "reemergente" ou "emergente" (WHO, 1995) ou como "doença zoonótica negligenciada" (WHO, 2010). O Centers for Disease Control - CDC (2010), de Atlanta, Georgia, EUA, define a raiva como uma doença prevenível com uso de vacinas. Em princípio, essa é uma doença mantida e perpetuada na natureza, principalmente pelos animais mamíferos carnívoros e pelos morcegos de diferentes hábitos alimentares, conhecidos como "reservatórios", "vetores" ou ainda "hospedeiros amplificadores" (VAN DER MERWE, 1982; FIELD et al., 2001).

\section{Histórico}

A raiva é temida desde a antiguidade em razão da sua natureza violenta, tanto em animais como no ser humano. O primeiro registro escrito aparece no Código de Eshnunna (cidade da antiga Mesopotâmia, perto de Bagdá, atual Iraque) de 1930 a.C: o proprietário de um cão que provocasse a morte de uma pessoa por raiva era multado pesadamente pelos legisladores (BLANCOU, 2004). O temor causado pela raiva transmitida por cães, lobos e chacais era geral tanto nas populações urbanas como nas rurais. No entanto o número de vítimas humanas, quando comparado com outras doenças infecciosas, jamais mereceu a atenção dos demógrafos. Nos registros antigos, aparecem descrições de doenças no homem e nos animais que se assemelham às da raiva. Aparentemente, os sinais da raiva não sofreram alterações 
por milhares de anos e as descobertas da epidemiologia molecular atestam que algumas dessas amostras de vírus teriam surgido há milhares de anos (BLANCOU, 2004). No tratado médico intitulado "De Modo Prognosticandi et Curandi Febres", escrito por Frederico Grisogono, da Era da Renascença, e publicado em Veneza em 1528, consta que "no caso da mordedura de um cão raivoso o processo leva vários meses, porque o veneno fica escondido no sangue por 3, 4, ou 5 meses até o coração tornar-se infectado. Quando o coração é afetado, seguem-se alterações abruptas e reações adversas - o paciente começa a perder sua memória, tem medo de água e morde com mordida venenosa e contagiosa, em consequência à agressão por um cão raivoso" (MUTINELLI et al., 2004). Outro médico italiano, Girolamo Fracastoro, no seu tratado " $D e$ Contagione et Contagiosis Morbis et Curatione", de 1530, descreveu que a doença era transmitida por meio da saliva de um animal infectado e o período de incubação não era inferior a 20 dias, em média de 30 dias, podendo estender-se de quatro a cinco meses ou, em raras vezes, de um a cinco anos (FERREIRA, 2005).

$\mathrm{Na}$ metade do século XVIII, a raiva urbana que acomete os cães surgiu na Europa, transmitida provavelmente por um animal silvestre (desconhecido), devido principalmente ao aumento da população de cães associado às grandes aglomerações humanas (ADAMSON, 1977). Os cães infectados com o vírus da raiva viajaram pelo mundo com os colonizadores europeus, disseminando o vírus para novos continentes e territórios. Subsequente à introdução da doença para novas áreas geográficas, o vírus pode ter sido transmitido para novas espécies de animais silvestres, o que, ao longo do tempo, possibilitou a evolução para novas estirpes de vírus. Os estudos moleculares sugerem que a Europa foi origem do vírus da raiva para o mundo, transmitido pelos cães, e o vírus foi denominado de "linhagem cosmopolita" (NADIN-DAVIS; BINGHAM, 2004).

\section{Distribuição geográfica}

\section{África}

É provável que a raiva esteja presente no Norte da África por milênios, uma vez que as civilizações humanas dessa região têm mantido comunicação com a região do Oriente Médio e Sul da Europa, onde a ocorrência da doença é conhecida desde a antiguidade. No entanto, a raiva transmitida pelos cães não era comum na África antes do estabelecimento de colonizadores europeus. Há registros de ocorrência da raiva canina na África do Sul entre 1770 e 1880 . Entretanto as primeiras constatações confiáveis aconteceram no final do século XIX, quando unidades do Instituto Pasteur foram estabelecidas na Argélia e na Tunísia, para a produção de vacina antirrábica destinada à imunização humana. $\mathrm{O}$ primeiro foco de raiva na África Subsaariana aconteceu em 1893, em Port Elizabeth, na costa Sudoeste da África do Sul, atingindo principalmente cães, gatos e herbívoros domésticos. A epidemia foi relacionada à importação de um cão da raça aire dale terrier da Inglaterra em 1892. A colonização europeia introduziu a raiva em toda a África Oriental e Ocidental, e os estudos de análises antigênicas e genéticas realizadas com as amostras de vírus isoladas da região Sul indicaram que há, pelo menos, dois biótipos distintos de raiva terrestre. Um biótipo é mantido em cães domésticos e canídeos silvestres, enquanto que o outro biótipo está associado com vários herpestídeos (Cynictis penicillata, Galerella sanguinea, Suricata suricatta) e viverrídeos (Genetta genetta) (NADIN-DAVIS; BINGHAM, 2004).

\section{América do Norte (Canadá e os Estados Unidos da Amé- rica - EUA)}

$O$ primeiro registro da raiva canina nos EUA aconteceu no Estado da Virgínia em 1753 e no final do século atingiu a costa Oeste dos EUA. No Canadá, o primeiro caso humano foi registrado em 1819 , tendo como transmissor uma raposa. O segundo caso ocorreu em Quebec, em 1839, associado a um cão. Casos esporádicos de raiva foram registrados ao Sul de Saskatchewan, provavelmente transmitidos por cães introduzidos do Estado de Dakota do Norte, EUA. Entre 1907 e 1945, foram relatadas epidemias de raiva em cães em Ontário e Quebec, com cães raivosos cruzando o Estado de Nova Iorque através da península do Niágara.

Em relação à raiva em animais silvestres, lobos e raposas com sinais de raiva foram encontrados em Ohio, no início de 180o. Em Massachusetts, as raposas já haviam sido incriminadas por causarem raiva em cães em 1812. As epidemias de raiva em animais silvestres envolviam principalmente as raposas-cinzentas (Urocyon cinereoargenteus) e as raposas-vermelhas (Vulpes vulpes), no estado da Flórida entre 1953 e 1958. Outros canídeos silvestres, como as raposas do Ártico (Alopex lagopus), são importantes reservatórios no Norte do Continente Americano, conhecidas desde a época de 1800 na Groenlândia. A partir de 1907, casos de raiva em cães e em humanos foram registrados no Alasca e Norte do Canadá. Outros carnívoros silvestres, como o cangambá (striped skunk, Mephitis mephitis; spotted skunk, Spirogale gracilis, Spirogale putorius), são conhecidos como fontes de infecção da raiva ao ser humano, com o registro mais 
antigo datado de 1826 no Estado da Califórnia, e desde 1940 o cangambá tem sido reconhecido como importante reservatório da raiva nos EUA e no Canadá. Em 1988, no Texas, na região de fronteira com o México, uma variante do vírus da raiva de cão foi responsável por uma epidemia em coiotes (Canis latrans).

A partir de 1947, surgiu uma variante do vírus da raiva em raccoons (Procyon lotor) no Estado da Flórida. $\mathrm{Na}$ década de 50 do século passado, a doença tornou-se endêmica na Costa Leste dos EUA e, em 1999, a epidemia atingiu os raccoons da Província de Ontário, Canadá, atravessando o rio Saint Lawrence (NADIN-DAVIS; BINGHAM, 2004).

\section{América Latina e Caribe}

Anterior ao estabelecimento da colonização europeia, não há registros de ocorrência da raiva canina na América do Sul. No México, a doença era conhecida desde 1709, enquanto que, no Peru, foi reconhecida em 1803 , e na Argentina, em 1806, em cães de caça introduzidos pelos soldados ingleses. O Uruguai registrou o primeiro caso em 1807, a Colômbia em 1810 e o Chile em 1835 . No final do século XX, numerosos casos foram registrados no México e no Brasil, enquanto Equador e Colômbia registraram menor número de casos (NADIN-DAVIS; BINGHAM, 2004).

Um estudo sobre a história evolutiva do vírus da raiva canina no Brasil, realizado por meio de análise filogenética, indicou que a introdução do vírus ocorreu por volta do final do século XIX e no início do século XX, muito tempo depois do período de colonização europeia. No entanto, esse período corresponde ao de grande movimento imigratório da Europa para o Brasil. O vírus da raiva posteriormente disseminou-se entre os animais carnívoros nativos durante o século XX, quando ocorreu o processo acelerado de desenvolvimento e urbanização no país (KOBAYASHI et al., 2011).

No Nordeste do Brasil, variantes do vírus da raiva canina foram isoladas de cachorros-do-mato (Cerdocyonthous) (CARNIELI et al., 2009) e raposinhas do Nordeste (Dusicyon vetulus) (BERNARDI et al., 2005), além de uma variante do vírus da raiva isolada de saguis (Callithrix jacchus) (BATISTA-MORAIS et al., 20oo).

No Caribe, a raiva em cães era conhecida desde a época da colonização espanhola, como em Barbados (1741), Guadalupe (1776), República Dominicana e Jamaica (1783). O mangusto (Herpestes auropunctatus), introduzido da Índia nas décadas de 1870 e 1880 para combater os roedores nas plantações de cana-de-açúcar, inicialmente, na Jamaica e, posteriormente, em outras ilhas caribenhas, é considerado importante reservatório para o vírus da raiva em Cuba, Granada, República Dominicana, Haiti e Porto Rico (NADIN-DAVIS; BINGHAM, 2004).

\section{Oriente Médio, Ásia e Oceania}

Uma revisão histórica da raiva menciona vários relatos de raiva em cães na Turquia, em 1586. Por volta de 1850, um incidente de raiva na cidade de Adália, território turco, envolveu um lobo raivoso que havia atacado mais de cem pessoas. Várias delas apresentaram quadro de raiva e morreram semanas depois. $\mathrm{Na} C h i n a$, o primeiro relato da raiva humana aconteceu em 1857, em Hong Kong, causado por um cão inglês, e o segundo caso aconteceu em Cantão, no ano de 1860. Alguns nativos chineses e dois europeus que moravam próximo à cidade de Beijing morreram devido à hidrofobia causada por cães pertencentes aos europeus. Assim, a raiva passou então a ser conhecida como doença comum em cães criados pelos europeus (NADIN-DAVIS; BINGHAM, 2004).

Em 1893, na cidade de Nagasaki, Japão, ocorreu uma epidemia de raiva em um bairro habitado por estrangeiros, com 76 pessoas agredidas por cães e dez óbitos humanos. Na província de Aomori, Norte do Japão, um cão infectado procedente da Rússia agrediu 47 pessoas e 11 delas foram a óbito. O Japão registrou muitos casos de raiva a cada ano, pelo menos até 1906, e em 1923 ocorreu uma epidemia com 235 mortes humanas. Entre 1959 e 1968, foram considerados livres de raiva Hong Kong (último caso em 1955), Taiwan (desde 1959), Japão (1956), Malásia e Cingapura (último caso em 1953) (NADINDAVIS; BINGHAM, 2004).

Índia e Filipinas atualmente registram maior número de ocorrência de raiva na região Sudeste da Ásia. Outros países, como Tailândia e Indonésia, apresentam um número elevado de casos de raiva humana, assim como Sri Lanka e países da Indochina. Os reservatórios silvestres da raiva são virtualmente desconhecidos na Ásia e, em muitas regiões tropicais, o "raccoon-dog" (Nictereutes procyonoides) está migrando da Ásia Central para a Europa, representando uma séria ameaça à reintrodução do vírus da raiva para os cães e raposas da Europa Ocidental. Na Jordânia e Israel, lobos e chacais são os principais reservatórios do vírus da raiva (YAKOBSON; DAVID; ALDOMY, 2004), assim como no Irã, Afeganistão, Paquistão, Nepal e Índia (NADINDAVIS; BINGHAM, 2004).

Por outro lado, as ilhas do Pacífico, bem como a Austrália e a Nova Zelândia, têm conseguido manter-se livre da raiva. A Austrália apresentou um caso de raiva canina na Tasmânia em 1867 e, desde então, mantém-se livre da doença (NADIN-DAVIS; BINGHAM, 2004). 


\section{Europa}

Na Idade Média, na Europa e na região Mediterrânea, os reservatórios mais importantes eram os cães, lobos e chacais. Os primeiros perambulavam pelas ruas, por isso mesmo as amostras de vírus isoladas de cães e de outros animais foram denominadas de "vírus de rua" (street virus ou vírus de calle). Nos países da Europa Ocidental, após o controle da raiva em cães, a doença passou a ocorrer quase exclusivamente em animais silvestres. $\mathrm{O}$ esforço para controlar a doença em animais mamíferos terrestres começou com ações voltadas para a população de raposas-vermelhas (Vulpes vulpes), com utilização de iscas contendo vacina antirrábica. Ao controlar a raiva em animais silvestres, alguns países da Europa Ocidental atingiram o status de países livres de raiva, como Holanda (1991), Suíça (1999), França (2000), Bélgica e Luxemburgo (2001), e República Tcheca (2004) (NADIN-DAVIS; BINGHAM, 2004).

\section{A raiva em morcegos}

No início do século passado, uma estranha doença acometia os bovinos e equídeos no Estado de Santa Catarina. Inicialmente, a doença foi diagnosticada como peste bovina. No entanto Carini (1911) foi o primeiro a diagnosticar raiva em um bovino morto por essa doença e mencionou em sua publicação que o morcego hematófago poderia ser o reservatório do vírus. Os pesquisadores da época, porém, consideraram o fato como "fantasia tropical". Pouco tempo depois, Haupt e Rehaag (1925) confirmaram o envolvimento do morcego hematófago Desmodus rotundus na transmissão da doença aos bovinos. Entre 1925 e 1929, foi registrada a ocorrência de botulismo em bovinos e poliomielite ascendente em seres humanos, na ilha de Trindade, no Caribe (CARNEIRO, 1936). Dois médicos americanos desfizeram o erro diagnóstico: a doença em bovinos e humanos tratavase de raiva transmitida pelos morcegos hematófagos (PAWAN, 1936).

Nos episódios de Santa Catarina, o morcego frugívoro Phyllostoma superciliatum, (atualmente Artibeus lituratus) foi diagnosticado como positivo para raiva por Haupt e Rehaag, porém, aparentemente, o primeiro diagnóstico da raiva em morcego não hematófago foi realizado na ilha de Trindade, no morcego Artibeus planirostris (CARNEIRO, 1936). Investigações realizadas nos morcegos da ilha revelaram que 64 morcegos $D$. rotundus, quatro Artibeus planirostris e um morcego insetívoro Diclidurus albus estavam infectados com o vírus da raiva (PAWAN, 1936). Esses morcegos não hematófagos foram os únicos relatados com raiva antes dos anos 50 do século passado. No entanto esses achados não despertaram interesse nem mesmo contestações por pesquisadores, comparado ao que aconteceu com a descoberta da raiva nos morcegos hematófagos (KING; HAAGSMA; KAPPELER, 2004). Porém, não foi o que aconteceu após o relato de um menino mordido por um morcego insetívoro (Diclidus albus) infectado pelo vírus da raiva no Estado da Flórida, EUA (VENTERS et al., 1954). O fato despertou interesse em outras partes do mundo e já no final da década de 1950 a presença do vírus da raiva em morcegos não hematófagos tinha sido confirmada na maioria dos países da América Central, América do Sul, América do Norte, África e Europa (BAER; SMITH, 1991).

Na Ilha de Lagos, Nigéria, África, foi isolado do morcego frugívoro Eidolon helvum um vírus sorologicamente semelhante ao vírus da raiva e, na África do Sul, de vários morcegos insetívoros, nas décadas de 1960 e 1970, denominados de vírus relacionados à raiva (rabies-related vírus), por causar uma doença muito semelhante à raiva (SHOPE et al., 1970).

No Brasil, o vírus da raiva foi isolado de morcegos hematófagos Desmodus rotundus, Diphylla ecaudata e Diaemus youngi e de numerosas espécies de morcegos de hábitos alimentares distintos (UIEDA et al., 1996). A lista de morcegos positivos para raiva, de 1996 a 2009, inclui 41 espécies pertencentes a 25 gêneros e três famílias: Phyllostomidae (43,9\%), Vespertilionidae (29,3\%) e Molossidae (26,8\%) (SODRÉ; GAMA; ALMEIDA, 2010).

Todos os morcegos da Europa são de hábito insetívoro (famílias Rhinolophidae, Vespertilionidae e Molossidae) e o vírus da raiva foi isolado do morcego Nyctalus noctula na Iugoslávia, na década de 1950. Em Hamburgo, Alemanha, em 1954, um garoto foi mordido por um morcego não identificado. O cérebro do morcego foi negativo ao exame da raiva, porém foram encontrados numerosos corpúsculos de Negri nos cérebros de camundongos em sua primeira passagem. Nos 30 anos seguintes, os casos de raiva em morcegos foram diagnosticados intermitentemente em vários países europeus, porém os mesmos foram considerados como meras curiosidades científicas. Em 1985, na Dinamarca, país considerado livre da raiva, foi registrada uma epidemia de raiva em morcegos Epitesicus serotinus e, no final do século, a doença havia alcançado os morcegos de 17 países europeus, com mais de 600 casos. As espécies positivas para raiva incluem Nyctalus noctula, Myotis myotis, E. serotinus, Myotis dasycneme, Pipistrellus nathusii, Vespertillio murinus, Myotis daubentonii, e Pipistrellus pipistrellus. Porém, o grau de ameaça à saúde para os seres humanos e animais domésticos representado por esses morcegos insetívoros infectados continua desconhecido. Os morcegos positivos para a raiva foram encontrados na Polônia, Iugoslávia, Turquia, Tchecoslováquia, França, Espanha, Suíça, Eslováquia, Ucrânia, Reino Unido, Alemanha, Finlândia, dentre outros (KING, HAAGSMA; KAPPELER, 2004). 
Na Austrália, o vírus foi isolado do morcego frugívoro Pteropus alecto e de outros morcegos insetívoros, a partir de 1996 (FRASER et al., 1996). Da Ásia Central à Sibéria, outros morcegos insetívoros foram identificados como positivos para o vírus da raiva. Atualmente, as características desses vírus são utilizadas como base para a classificação de espécies dentro do gênero Lyssavirus (FOOKS, 2004).

\section{Ocorrência mundial}

Existem poucos dados sobre a ocorrência da raiva no mundo. A raiva é endêmica em mais de cem países. Alguns países constituídos por ilhas e arquipélagos, como Islândia, Japão e Reino Unido, e outros países da Europa, como Bélgica, Finlândia, França, Grécia, Noruega, Portugal, Espanha, Suécia e Suíça, são considerados livres de raiva. Países do continente americano como Uruguai, Barbados, Jamaica e muitas ilhas do Caribe Inglês não têm mais notificado a ocorrência da raiva em seus territórios nos últimos anos (WHO, 2005). O Uruguai, que era considerado país livre da doença, em 2007, registrou uma epidemia de raiva em bovinos transmitida pelos morcegos $D$. rotundus, nos arredores de Tranqueras, departamento de Rivera, a $450 \mathrm{~km}$ ao Norte de Montevidéu e a $50 \mathrm{~km}$ da cidade brasileira de Santana do Livramento (UOL, 2007).

Há estimativas de que anualmente morrem de raiva 55.0oo pessoas na África e na Ásia, especialmente em zonas rurais (intervalo de confiança, com $\alpha=0,10: 24.500$ - 90.800), com uma estimativa de morte de $56 \%$ na Ásia e $44 \%$ na África. Somente na Índia, essa estimativa é de 30.000 mortes/ano, isso é, uma incidência anual de três mortes a cada 100.000 pessoas (WHO, 2005). A estimativa de 30.000 a 50.000 mortes humanas/ano consta nos documentos intitulados World Survey of Rabies - WSR, elaborados pela Organização Mundial da Saúde (WHO). $\mathrm{Na}$ edição do $W S R \mathrm{n}^{\circ}$ 34, de 1998, a ocorrência mundial da raiva humana foi de 33.373 e 32.342 casos animais. Já na edição WSR no 35, de 1999, os casos humanos baixaram para 1.866, enquanto em animais foram 34.141 casos. É notória a discrepância nos dados de um ano para outro e a partir deste número não foi mais editada a série de publicação intitulada WSR pela WHO. No final da década de 90 do século passado, tornou-se disponível a versão eletrônica RABNET para recuperar os dados de ocorrência da raiva no mundo, através do endereço http://www. who.int/rabies/rabnet.

\section{Importância econômica e social}

Os prejuízos econômicos diretos causados pelas mortes de animais alcançam milhões de dólares/ano em países do continente americano em que a economia se baseia na produção de animais de interesse em saúde animal. Fora do Continente Americano, em locais em que não existem morcegos hematófagos, a ocorrência da raiva em animais domésticos é esporádica. Na América Latina, em 1984, o prejuízo econômico em consequência da raiva transmitida por morcegos hematófagos foi estimado em US $\$ 42$ milhões/ano, sendo que no Brasil esse valor se aproximava de US\$30 milhões (ACHA; MÁLAGA-ALBA, 1988).

\section{Importância em saúde pública}

Desde os tempos remotos, a raiva vem exigindo atenção dos governantes para o seu controle e, a partir do desenvolvimento de uma vacina antirrábica por Pasteur, há mais de cem anos, o perfil de ocorrência da raiva vem se alterando gradualmente nos países em que foram adotadas medidas de controle mais estritas voltadas para os reservatórios domésticos. A raiva humana determinada pela agressão por cães está decrescendo nas Américas, porém está se tornando cada vez mais frequente a participação de animais silvestres na transmissão da doença aos humanos (BELOTTO, 200o). No Estado do Pará, Brasil, foram registrados 22 óbitos humanos em 2004, e 24 mortes no Maranhão em 2005, com a maioria dos casos relacionada à transmissão pelos morcegos D. rotundus(BRASIL, 2011).

No mundo, os cães ainda representam 90\% dos casos de exposição à raiva e aproximadamente $99 \%$ das mortes humanas pela raiva. Em muitos países em desenvolvimento, os custos desses programas impedem a sua execução. Em países desenvolvidos, o controle efetivo da raiva em cães representa um gasto adicional de recursos públicos. Nos EUA, esse custo foi estimado em mais de US $\$ 300$ milhões anuais, sendo a maioria destinada para a vacinação de cães. No Brasil, o orçamento destinado para a prevenção da raiva alcançou US $\$ 28$ milhões, em 2004. A cada ano, devem ser revacinados milhões de animais, e a reintrodução da doença através de transporte de animais infectados procedentes de outras áreas poderia representar possíveis falhas no programa (WHO, 2005).

\section{Etiologia \\ $\mathrm{O}$ vírus da raiva}

Até pouco mais da metade do século passado, acreditava-se na etiologia única do vírus da raiva acometendo um grande número de mamíferos. Os vírus apresentam forma cilíndrica semelhante a uma bala de revólver, com uma extremidade arredondada e outra mais plana, com diâmetro médio de $75 \mathrm{~nm}$ e comprimento de 100 a 300 $\mathrm{nm}$, variando de acordo com a amostra considerada (TORDO, 1996). 
O vírus da raiva é envelopado e sensível aos solventes orgânicos, como solução de sabão, éter, clorofórmio, acetona, etanol, solução de iodo e compostos de amônio quaternário, assim como formol, fenol, bicloreto de mercúrio, sais minerais, ácidos e álcalis fortes, detergentes, agentes físicos (calor, luz ultravioleta) e às condições ambientais, como dessecação, luminosidade e temperatura excessiva (WUNNER, 1991; KAPLAN, 1996).

Porém, o vírus permanece viável quando mantido em solução salina contendo 50\% de glicerina (AGUILARSETIÉN et al., 2003), no estado liofilizado a $4^{\circ} \mathrm{C}$, em fragmentos de tecido nervoso mantidos entre -30 e $-60^{\circ} \mathrm{C}$, ou em suspensões acrescidas de soro, leite ou gema de ovo esterilizado, que prolongam a viabilidade do vírus (MAYR; GUERREIRO, 1972).

O genoma dos lissavírus é composto por uma cadeia de RNA de fita simples não segmentado e não infeccioso, com polaridade negativa, com tamanho variando de 11 a 15 $\mathrm{kb}$ e peso molecular de 3,5 a 4,6 × $10^{6} \mathrm{KD}$ altons. O RNA genômico é transcrito em cinco RNAs mensageiros subgenômicos, que são traduzidos em cinco proteínas, mantendo a seguinte sequência: a nucleoproteína $\mathrm{N}$, a fosfoproteína $\mathrm{P}$ (previamente denominada $\mathrm{M} 1$ ), a proteína da matriz $\mathrm{M}$ (previamente denominada $\mathrm{M} 2$ ), a glicoproteína $\mathrm{G}$ e a RNA polimerase-dependente (L). O gene apresenta duas regiões intergênicas não codificantes: uma está situada entre os genes que codificam $\mathrm{M}$ e $\mathrm{G}$ e a outra, entre os genes que codificam $G$ e $L$, a qual foi previamente chamada "pseudogene - " $\psi$ " (BROOKES et al., 2004).

Os primeiros estudos filogenéticos do vírus do gênero Lyssavirus foram realizados com sequência completa da nucleoproteína N. Posteriormente, surgiram outros estudos utilizando sequência parcial ou completa da nucleoproteína $\mathrm{N}$, segmentos do gene $\mathrm{G}$ e região intergênica G-L, e sequência completa do gene P. Com o uso de técnicas da bioinformática, é possível comparar geneticamente uma amostra viral recém-isolada com outra registrada no GenBank, após o sequenciamento genômico, estudo do alinhamento (THOMPSON et al., 1997) e confecção do dendrograma, para permitir a análise filogenética e estudo de epidemiologia molecular (PAGE, 1996). As sequências do nucleotídeo estão depositadas no EMBL/GenBank78 (PATHINFO, 2006), identificados com números para acesso, por exemplo, D10499; Ko2869; AB117969; M61047.

\section{Taxonomia}

A Comissão Internacional de Taxonomia dos Vírus (ICTV, 2009) inclui os vírus da raiva dentro do gênero Lyssavirus, família Rhabdoviridae, ordem Mononegavirales, representados por onze espécies: Aravan virus (ARAV), Australian bat lyssavirus (ABLV), Duvenhage virus (DUVV), European bat lyssavirus 1 (EBLV-1), European bat lyssavirus 2(EBLV-2), Irkut virus (IKV), Khujand virus (KHUJV), Lagos batvirus (LBV), Mokola virus (MOKV), Rabies virus (RABV) e o West Caucasian bat virus (WCBV).

Os vírus do gênero Lyssavirus eram diferenciados em quatro sorotipos distintos, a saber: sorotipo 1 ou os vírus "clássicos" da raiva; o sorotipo 2 ou o Lagos bat vírus; sorotipo 3 ou Mokola vírus, isolado do musaranho Crocidura sp., em 1968 na Nigéria, e o sorotipo 4, Duvenhage vírus, isolado de um paciente humano que havia sido mordido por um morcego insetívoro não identificado na África do Sul, em 1970. Os sorotipos de 2 a 4 foram denominados de vírus relacionados à raiva (rabies-related ou rabies-like) (SHOPE et al., 1970). Outros vírus isolados de morcegos insetívoros da Europa haviam sido designados pelo nome do seu gênero, o European bat Lyssavirus tipo 1, isolado do morcego insetívoro Epitesicus serotinus da Dinamarca em 1985, e o European bat Lyssavirus tipo 2 (EBLV-2), isolado de um biólogo suíço morto após manifestar doença semelhante à raiva, na Finlândia, em 1985, e mais tarde isolados de morcegos insetívoros Myotis daubentoni e Myotis dasicneme, da Europa (FOOKS, 2004).

A partir de 1994, os sorotipos passaram a ser denominados de genótipos e os sorotipos 1 a 4, constituídos pelos RABV, LBV, MOKV e DUVV, passaram a ser designados como genótipos 1, 2, 3 e 4, respectivamente. Os EBLV-1 e EBLV-2 isolados da Europa foram designados como genótipos 5 e 6 (WHO, 1994), e os vírus isolados de morcegos frugívoros e insetívoros da Austrália, como genótipo 7 (GOULD et al., 1998).

Outros quatro lissavírus foram incluídos no gênero Lyssavirus: Aravan vírus (ARAV) como genótipo 8, isolado do morcego insetívoro Myotis blythi, no Quirguistão, Ásia Central (ARAI et al., 2003); Khujand vírus (KHUV), genótipo 9, isolado do morcego insetívoro Myotis mystacinus, no Norte de Tajiquistão (KUZMIN et al., 2003); e Irkut vírus (IRKV), genótipo 10, isolado do morcego Murina leucogaster, na Sibéria Oriental. O lissavírus isolado do morcego Miniopterus schreibersi da montanha do Cáucaso passou a ser denominado de genótipo 11, "West Caucasian Bat lyssavirus (WCBV)" (BOTVINKIN et al., 2003). Mais recentemente, o Shimoni vírus (SHIBV) isolado do morcego Hipposideros commersoni no Quênia, foi descrito como nova espécie do gênero Lyssavirus (KUZMIN et al., 2010).

Os lissavírus foram categorizados em dois ou três filogrupos distintos. Os genótipos 1, 4, 5, 6 e 7, o Aravan vírus, Khujand vírus e o Irkut vírus compõem o filogrupo I. O grupo II contém os dois vírus africanos divergentes, 
os genótipos 2 e 3. O mais divergente WCBV foi colocado à parte, no filogrupo III. Os lyssavírus LBV, MOKV e DUVV estão restritos geograficamente à África, os EBLVs, aos morcegos insetívoros da Europa e o ABLV, aos morcegos frugívoros e insetívoros da Austrália (FOOKS et al., 2003).

Apesar do número cada vez mais crescente de espécies no gênero Lyssavírus, a World Organisation for Animal Health (OIE) considera como sendo raiva apenas a doença causada pelos vírus do genótipo 1 (OIE, 2011). Os vírus relacionados à raiva (genótipos 2 a 4) foram denominados de "lissavírus não raiva", incluindo outros genótipos (5 a 11) que são conhecidos genericamente por lissavírus. A doença neurológica observada no homem e nos animais é denominada de lissavirose (THE CENTER FOR FOOD SECURITY \& PUBLIC HEALTH, 2009).

Os lissavírus (EBL1 e EBL2) isolados de morcegos insetívoros da Europa são mesmo vírus da raiva? Embora Shope et al. (1970) tenham introduzido o termo "vírus relacionados à raiva", pois a doença causada pelo LBV era indistinguível da raiva clássica (genótipo 1), esse termo deve ser abandonado e os lissavírus devem ser tratados como agentes causadores da raiva (KING, HAAGSMA; KAPPELER, 2004).

\section{Hospedeiros}

No mundo, os hospedeiros considerados "reservatórios" variam conforme a localização geográfica. $\mathrm{Na}$ América do Norte, com o desaparecimento do vírus na população de cães e gatos domésticos, os reservatórios silvestres do vírus da raiva são raposas (Vulpes vulpes), raccoons (Procyon lotor), cangambá (Mephitis mephitis), lobos (Canis lupus), coiotes (Canis latrans), raposas do ártico (Alopex lagopus) e diferentes espécies de morcegos insetívoros. No México, além de coiotes e gambás, o vírus é encontrado na população de morcegos hematófagos e não hematófagos.

$\mathrm{Na}$ Europa, as raposas-vermelhas (Vulpes vulpes) e o raccoon-dog (Nictereutes procyonoides) são os mais citados. No Continente Africano, além de cães, os carnívoros silvestres, tais como hienas (Hyaena brunnea, Crocuta crocuta), chacais (Canis simensis, Canis mesomelas, Canis adustus), mangusto amarelo (Cynictis penicillata), raposas (Otocyon megalotis, Vulpes sp) e civetas (Civettictiscivetta), são os mais importantes (MACINNES, 1988; RUPPRECHT; STÖHR; MEREDITH, 2001).

Nas ilhas do Caribe Espanhol, o vírus é isolado do mangusto comum (Herpestes auropunctatus). Na América do Sul, há relatos de isolamento de guaxinim (Procyoncancrivorous), lobo-guará (Crysocyonbrachyurus), sagui do Nordeste (Callithrix jacchus), raposa do Nordeste (Dusicyon vetulus), coati (Nasua nasua), cachorro-domato (Cerdocyon thous), gato-do-mato (Leopardus tigrinus), onça-pintada (Panthera onca), além de numerosas espécies de morcegos (CORRÊA; PASSOS, 2001).

Dentre as espécies consideradas como hospedeiros terminais, os bovinos (Bos taurus, Bos indicus), equinos (Equus caballus), caprinos (Capra hircus), ovinos (Ovis aries), búfalos domésticos (Bubalus bubalis) e silvestres, suínos (Sus domesticus), javalis (Sus scrofa), iaques (Bos grunniens), diferentes espécies de cervos, lhamas (Lama guanicoe), elefantes, dentre outros, são as espécies não carnívoras mais envolvidas com os episódios da raiva. Por sua vez, a raiva envolvendo roedores como coelhos ( $L e$ pus sp), cobaias (Cavea porcellus), hamsters (Mesocricetus auratus) e esquilos (Callosciurus $\mathrm{sp}$ ) é rara na literatura (SODJA; MATOUCH; LIM, 1971; BROWN; TINGPALAPONG; ANDREWS, 1979; SVRCEK; ONDREJKA; MLYNARCIKOVA, 1984; WINKLER, 1991;MATTOS; MATTOS; RUPPRECHT, 2001), muito provavelmente porque esses animais não resistiriam ao ataque de um animal raivoso como cães, gatos ou outros reservatórios carnívoros (CHILDS et al., 1997).

\section{Referências}

1. ACHA, P.N.; MÁLAGA-ALBA, A. Economic lossesdue to Desmodus rotundus. In GREENHALL, A.M.; SCHMIDT, U. Natural history of vampire bats. Boca Raton: CRC Press, 1988. p.207-214

2. ACHA, P.N.; SZYFRES, B. Zoonosis y enfermedades transmisibles comunes al hom bre y a los nimales. 3. ed. Washington: Organización Panamericana De La Salud, 2003. v.2, p. 425.

3. ADAMSON, P.B. The spread of rabies into Europe and the probable origin of this disease in antiquity. Journal of the Royal Asiatic Society of Great Britain \& Ireland, Cambridge, v.2, p.140-4, 1977.

4. AGUILAR-SETIÉN, A.; AGUILA-TECUATL, H.; TESORO-CRUZ, E.; RAMOS-RAMIREZ, L.; KRETSCHMER, R.S. Preservation of rabies virus RNA from brain tissue using glycerine. Transactions of the Royal Society of Tropical Medicine and Hygiene, London, v.97, n.5, p.547-549, 2003.

5. ARAI, Y.T.; KUZMIN, I.V.; KAMEOKA, Y.; BOTVINKIN, A.D. New Lyssavirus genotype from the lesser mouse-eared bat (Myotis blythi), Kyrghystan. Emerging Infectious Diseases, Atlanta, v.9, n.3, p.333-337, 2003.

6. BAER, G.M. The Natural History of Rabies. 2. ed. Boca Raton: CRC Press, 1991. p. 620

7. BAER, G.M.; SMITH, J.S. Rabies in non-hematophagous bats. In: BAER, G.M. The Natural History of Rabies. Boca Raton: CRC Press, 1991. p. 341-366.

8. BATISTA-MORAIS, N.; NEILSON-ROLIM, B.; MATTOS-CHAVES, H.H.; DE BRITONETO, J.; MARIA-DA-SILVA, L. Rabies in tamarins (Callithrix jacchus) in the state of Ceará, Brazil, a distinct viral variant? Memórias do Instituto Oswaldo Cruz, v.95, n.5, p.609-610, 2000.

9. BELL, J.F.; GONZALEZ, M.A.; DIAZ, A.M.; MOORE, G.J. Nonfatal rabies in dogs: experimental studies and results of a survey. American Journal of Veterinary Research, Chicago, v.32, n.12, p.2049-2058, 1971 
10. BELOTTO, A.J. Situação da raiva no mundo e perspectivas de eliminação da raiva transmitida pelo cão na América Latina. In: SEMINÁRIO INTERNACIONAL DE RAIVA, 2000, São Paulo. Anais... São Paulo, 2000. p. 20-21.

11. BERNARDI, F.; NADIN-DAVIS, S.A.; WANDELER, A.I.; ARMASTRONG, J.; GOMES, A.A.; LIMA, F.S.; NOGUEIRA, F.R.; ITO, F.H. Antigenic and genetic characterization of rabies viruses isolated from domestic and wild animals identifies the hoary fox as rabies reservoir. Journal of General Virology, London, v.86, n.11, p.3153-3162, 2005.

12. BLANCOU, J. Rabies in Europe and the Mediterranean Basin: From antiquity to the 19th century. In: KING, A.A.; FOOKS, A.R.; AUBERT, M.; WANDELER, A.I. Historical Perspective of Rabies in Europe and the Mediterranean Basin. Paris: World Organization for Animal Health (OIE), 2004.p.15-24.

13. BOTVINKIN, A.D.; POLESCHUK, E.M.; KUZMIN, I.V.; BORISOVA, T.I.; GAZARYAN, S.V.; YAGER, P.; RUPPRECHT, C.E. Novel lyssaviruses isolated from bats in Russia. Emerging Infectious Diseases, Atlanta, v.9, n.12, p.1623-1625, 2003.

14. BRASIL. Ministério da Saúde. Secretaria de Vigilância em Saúde. Casos confirmados de Raiva Humana segundo UF de residência. Brasil, Grandes Regióes e Unidades Federadas. 1990 a 2011*. 2011. Disponível em: <http://portal.saude.gov.br/portal/ arquivos/pdf/casos_confirmados_raiva_humana_90_11.pdf $>$. Acesso em: 01 jun. 2011.

15. BROOKES, S.M.; MCELHINNEY, L.M.; JOHNSON, N.; BADRANE, H.; TORDO, N.; FOOKS, A.R. Rabies virus variants and molecular epidemiology in Europe. In: KING, A.A.; FOOKS, A.R.; AUBERT, M.; WANDELER, A.I. Historical Perspective of Rabies in Europe and the Mediterranean Basin. Paris: World Organization for Animal Health (OIE), 2004. p.243-258.

16. BROWN, J.L.; TINGPALAPONG, M.; ANDREWS, W.K. Serological survey of feral rodents in Thailand for evidence of rabies virus infection. Journal of Wildlife Diseases, Ames, v.15, n.4, p.601-606, 1979.

17. CARINI, A. Sur une grande épizootie de rage. Annales de L'Institut Pasteur, Paris, v.25, p.843-846, 1911.

18. CARNEIRO, V. As epizootias de raiva na América e o papel dos morcegos hematófagos. Arquivos do Instituto Biológico, São Paulo, v.7, p. 273-321, 1936

19. CARNIELI JR., P.; CASTILHO, J.; FAHL, W.O.; VÉRAS, N.M.; CARRIELI, M.L.; KOTAIT, I. Molecular characterization of rabies virus isolates from dogs and crab-eating foxes in Northeastern Brazil. Virus Research, Amsterdam, v.141, n.1, p.81-89, 2009.

20. CENTERS FOR DISEASE CONTROL AND PREVENTION (CDC). Vaccines and preventable diseases: rabies vaccination. 2010. Disponivel em: <http://www.cdc.gov/ vaccines/vpd-vac/rabies/default.htm>. Acesso em: 02 maio 2010.

21. CHILDS, J.E.; COLBY, L.; KREBS, J.W.; STRINE, T.; FELLER, M.; NOAH, D.; DRENZEK, C.; SMITH, J.S.; RUPPRECHT, C.E. Surveillance and spatiotemporal associations of rabies in rodents and lagomorphs in the United States, 1985-1994. Journal of Wildlife Diseases, Ames, v.33, n.1, p.20-27, 1997.

22. CORREAA, S.H.R.; PASSOS, E.C. Wild animals and public health. In: FOWLER, M.E. Biology, medicine and surgery of South American wild animals. Ames: lowa State University Press, 2001. p.493-499.

23. FERREIRA, L.A.P. O conceito de contágio de Girolamo Fracastoro nas teses sobre sífilis e tuberculose, 2008. $159 \mathrm{f}$. Tese (Doutorado em Enfermagem) - Curso de PósGraduação em Enfermagem, Universidade Federal de Santa Catarina, Florianópolis, 2008.

24. FIELD, H.; YOUNG, P.; YOB, J.M.; MILLS, J.; HALL, L.; MACKENZIE, J. The natural history of Hendra and Nipah viruses. Microbes and Infection, Paris, v.3, n.4, p.307314, 2001.

25. FRASER, G.C.; HOOPER, P.T.; LUNT, R.A.; GOULD, A.R.; GLEESON, A.D.; RUSSEL, G.M.; KATTENBELT, J.A. Encephalitis caused by a Lyssavirus in fruit bats in Australia. Emerging Infectious Diseases, Atlanta, v.2, n.4, p.327-331, 1996.

26. FOOKS, A. The challenge of new and emerging lyssaviruses. Expert Review of Vaccines, London, v.3, n.4, p.333-336, 2004.
27. FOOKS, A.R.; BROOKES, S.M.; JOHNSON, N.; MCELHINNEY, L.M.; HUTSON, A. $M$. European bat lyssaviruses: an emerging zoonosis. Epidemiology and infection, Cambridge, v.131, n.3, p.1029-1039, 2003.

28. GOULD, A.R.; HYATT, A.D.; LUNT, R.; KATTENBELT, J.A.; HENGSTBERGER, S.; BLACKSELL, S.D. Characterisation of a novel lyssavirus isolated from Pteropid bats in Australia. Virus Research, Amsterdam, v.54, n.2, p.165-87, 1998.

29. HAUPT, H.; REHAAG, H. Raiva epizoótica nos rebanhos de Santa Catarina, transmitida por morcegos. Boletim da Sociedade Brasileira de Medicina Veterinária, Nova Iguaçu, v.2, p.17-47, 1925.

30. ICTV. INTERNATIONAL COMMITTEE ON TAXONOMY OF VIRUSES. Virus TaXonomy: 2009 Release. Disponivel em: <http://www.ictvonline.org/virusTaxonomy. asp?bhcp=1>. Acesso em: 12 jul. 2010.

31. KAPLAN, M.M. Safety precautions in handling rabies virus. In: MESLIN, F.X.; KAPLAN, M.M.; KOPROWSKI, H. Laboratory techniques in rabies. Geneva: World Health Organization, 1996.p.3-8.

32. KING, A.A.; HAAGSMA, J.; KAPPELER, A. Lyssavirus infections in European bats. In: KING, A. A.; FOOKS, A. R.; AUBERT, M.; WANDELER A. I. Historical Perspectives of Rabies in Europe and the Mediterranean Basin. Paris: World Organization for Animal Health (OIE), 2004.p.221-241.

33. KOBAYASHI, Y.; SUZUKI, Y.; ITOU, T.; ITO, F.H.; SAKAI, T.; GOJOBORI, T. Evolutionary history of dog rabies in Brazil. The Journal of General Virology, London, v.92, n.1, p.85-90, 2011.

34. KUZMIN, I.V.; MAYER, A.E.; NIEZGODA, M.; MARKOTTER, W.; AGWANDA, B.; BREIMAN, R.F.; RUPPRECHT, C.E. Shimoni bat virus, a new representative of the Lyssavirus genus. Virus Research, Amsterdam, v.149, n.2, p.197-210, 2010.

35. KUZMIN, I.V.; ORCIARI, L.A.; ARAI, Y.T.; SMITH, J.S.; HANLON, C.A.; KAMEOKA, Y.; RUPPRECHT, C.E. Bat lyssaviruses (Aravan and Khujand) from Central Asia: phylogenetic relationships according to N, P and G gene sequences. Virus Research, Amsterdam, v.97, n.2, p.65-79, 2003

36. MACHADO, C.G. Reflexões sobre a raiva humana. Boletim do Instituto Pasteur, São Paulo, v.1, n.1, p.3-6, 1996

37. MACINNES, C.D. Control of wildlife rabies: The Americas. In: CAMPBELL, J.B.; CHARLTON, K.M. Rabies. Boston: Kluwer Academic Publishers, 1988. p.381-405.

38. MATTOS, C. A. de; MATTOS, C. C. de; RUPPRECHT, C. E. Rhabdoviruses. In: KNIPE, D. M.; HOWLEY, P. M. Fields' Virology. Philadelphia: Lippincott Williams \& Wilkins, 2001. p. $1245-1274$.

39. MAYR, A.; GUERREIRO, M.G. Vírus da raiva. In: Virologia Veterinária. Porto Alegre: Sulina, 1972. p.437.

40. MUTINELLI, F.; STANKOV, S.; HRISTOVSKI, M.; SEIMENIS, A.; THEOHARAKOU, H.; VODOPIJA, I. Rabies in Italy, Yugoslávia, Croatia, Bosnia, Slovenia, Macedonia, Albânia \& Greece. In: KING, A.A.; FOOKS, A.R.; AUBERT, M.; WANDELER, A.I. Historical Perspective of Rabies in Europe and the Mediterranean Basin. Paris: World Organization for Animal Health (OIE), 2004.p.93-118.

41. NADIN-DAVIS, S.A.; BINGHAM, J. Europe as a source of rabies for the rest of the world. In: KING, A.A.; FOOKS, A.R.; AUBERT, M.; WANDELER A.I. Historical Perspectives of Rabies in Europe and the Mediterranean Basin. Paris: World Organization for Animal Health (OIE), 2004.p.259-280.

42. NILSSON, M.R. Revisão do conceito de que a raiva é sempre fatal. Boletín de la Oficina Sanitaria Panamericana (OSP), Washington, v.68, n.6, p.486-94, 1970.

43. OIE. World Organisation for Animal Health. Rabies. In: Manual of Diagnostics Tests and Vaccines for Terrestrial Animals(NB: Version adopted in May 2011) 2011. Disponivel em: <http://www.oie.int/fileadmin/Home/eng/Health_standards/ tahm/2.01.13_RABIES.pdf> Acesso em: 08 ago. 2011.

44. PAGE, R.D. Treeview: anapplication to display phylogenetic trees on personal computers. Computer Applications in theBiosciences, Oxford, v.12, n.4, p.357-358, 1996. 
45. PATHINFO (PathogenInformation). Rabies. [2006]. Disponível em: <http://ci.vbi. vt.edu/pathinfo/pathogens/Rabies_virus_Info.shtml>. Acesso em: 15 abr. 2010.

46. PAWAN, J.L. The transmission of paralytic rabies in Trinidad by the vampire bat (Desmodus rotundus murinus Wagner, 1840). Annals of Tropical Medicine and Parasitology, Liverpool, v.30, n.4, p.101-130, 1936.

47. RUPPRECHT, C.E.; STÖHR, K.; MEREDITH, C. Rabies. In: WILLIAMS, E.S.; BARKER, I.K. Infectious Disease of Wild Mammals. Iowa: Iowa State University Press, 2001. p.3-36.

48. SHOPE, R.E.; MURPHY, F.A.; HARRISON, A.K.; CAUSEY, O.R.; KEMP, G.E.; SIMPSON, D.I.; MOORE, D.L. Two African viruses serologically and morphologically related to rabies virus. Journal of Virology, Baltimore, v.6, n.5, p.690-692, 1970.

49. SODJA, I.; MATOUCH, O.; LIM, D. Isolationof rabies-like virus frommurinerodents. JournalofHygiene, Epidemiology, Microbiology and Immunology, Prague, v.15, n.2, p.229-230, 1971.

50. SODRÉ, M.M.; GAMA, A.R.; ALMEIDA, M.F. Updated list of bat species positive for rabies in Brazil. Revista do Instituto de Medicina Tropical de São Paulo, São Paulo, v. 52, n.2, p.75-81, 2010.

51. SVRCEK, S.; ONDREJKA, R.; MLYNARCIKOVA, K.; SVEC, J. Rabies in common hamster (Cricetus cricetus) in Slovakia. Veterinární Medicína, Praha v.29, n.11, p.643652, 1984.

52. THE CENTER FOR FOOD SECURITY \& PUBLIC HEALTH. Rabies: Hydrophobia, Lyssa (Oct. 2009). Disponível em: <http://www.cfsph.iastate.edu/Factsheets/pdfs/rabies. pdf>. Acesso em: 12 maio 2010.

53. THOMPSON, J.D.; GIBSON, K.J.; PLEWNIAK, F.; JEANMOUGIN, F.; HIGGINS, D.G. The Clustal $X$ windows interface: flexible strategies for multiple sequence alignment aided by quality analysis tools. Nucleic Acids Research, London, v.25, n.24, p. 4876-4882, 1997.

54. TORDO, N. Characteristics and molecular biology of the rabies virus. In: MESLIN, F.X.; KAPLAN, M. M.; KOPROWSKI, H. Laboratory techniques in rabies. Geneva: World Health Organization, 1996. p.28-51

55. UIEDA, W.; HAYASHI, M.M.; GOMES, L.H.; SILVA, M.M.S. Espécies de quirópteros diagnosticados com raiva no Brasil. Boletim do Instituto Pasteur, São Paulo, v.1, n.2, p.17-35, 1996.

56. UOL. Economia. Últimas notícias. Morcegos transmitiram raiva a gado na fronteira Uruguai-Brasil. 2007. Disponível em: <http://economia.uol.com.br/ultnot/ afp/2007/10/31/ult35u56101.jhtm>. Acesso em: 03 maio 2011.
57. VAN DER MERWE, M. Bats as vectors of rabies. South African Journal of Science, Johannesburg, v.78, p.421-422, 1982.

58. VENTERS, H.D.; HOFFERT, W.R.; SCHATTERDAY, J.E.; HARDY, A.V. Rabies in bats in Florida. American Journal of Public Health, Albany, v.44, n.2, p.182-185, 1954.

59. WILKINSON, L. History. In: JACKSON, A.C.; WUNNER, W. Rabies. San Diego: Academic Press; 2002. p.1-21.

60. WINKLER, W.G. Rodent rabies. In: BAER, G.M. The natural history of rabies. Boca Raton: CRC Press, 1991. p.405-410.

61. WHO. WORLD HEALTH ORGANIZATION. Communicable diseases prevention and control: new, emerging and re-emerging infectious diseases. In: WORLD HEALTH ASSEMBLY, 48, 1995, Geneva. Switzerland: World Health Organization, 1995. (DocumentWHA48.13).

62. WHO. WORLD HEALTH ORGANIZATION. Rabies: A neglected zoonótico disease. [2010]. Disponível em: <http://www.who.int/rabies/en/>. Acesso em: 13 jul. 2010.

63. WHO. WORLD HEALTH ORGANIZATION. WHO Technical Report Series 931 - First Report. In: WHO Expert Consultation on Rabies. Geneva, Switzerland: World Health Organization, 2005. 88 p.

64. WHO. WORLD HEALTH ORGANIZATION. WHO Workshop onGenetic and AntigenicMolecular Epidemiologyof Lyssaviruses. Niagara Falls, Canada: World Health Organization, 1994. p.7.

65. WHO. WORLD HEALTH ORGANIZATION. World Survey of Rabies, N 34, 1998 Disponível em: <http://www.who.int/rabies/resources/en/wsr98_table1.pdf>. Acesso em: 14 jun. 2010

66. WHO. WORLD HEALTH ORGANIZATION. World Survey of Rabies, N 35, 1999. Geneva. Disponível em: <http://www.who.int/rabies/resources/wsr1999/en/>. Acesso em: 15 jun. 2010.

67. WUNNER, W.H. The chemical composition and molecular structure of rabies viruses. In: BAER, G.M. The Natural History of Rabies. Boca Raton: CRC Press, 1991. p.3167.

68. YAKOBSON, B.A.; DAVID, D.; ALDOMY, F. Rabies in Israel and Jordan. In: KING, A.A.; FOOKS, A.R.; AUBERT, M.; WANDELER A.I. Historical Perspectives of Rabies in Europe and the Mediterranean Basin. Paris: World Organization for Animal Health (OIE), 2004.p.171-183. 